\title{
Cuidador Informal Familiar: Relação familiar e a satisfação/insatisfação na gestão do cuidado
}

\section{Informal Family Caregiver: Family relationship and satisfaction / dissatisfaction in care management}

DOI: $10.46814 /$ lajdv2n6-011

Recebimento dos originais: 01/09/2020

Aceitação para publicação: 30/10/2020

\section{Lisneti Castro}

Doutorada em Psicologia da Educação/Departamento de Psicologia e Educação/Universidade de Aveiro- Universidade de Aveiro-Portugal

Instituição: APACID - Associação de Apoio a Cuidadores de Pessoas Dependentes

Endereço: Junta de Freguesia de São Bernardo, R. Cónego Maio 133 1Andar, 3810-089 Aveiro, Portugal

E-mail: lisneti_castro@yahoo.com.br

\section{Dayse Neri de Souza}

Doutorada em Ciências da Educação/ Universidade de Aveiro-Portugal Instituição: UNASP - Centro Universitário Adventista de São Paulo- Brasil

Endereço: Estr. Mun. Pastor Walter Boger, S/N - Lagoa Bonita I, Eng. Coelho - SP, 13445-970, Brasil

E-mail: dayse.souza@unasp.edu.br

\section{Anabela Pereira}

Doutorada em Psicologia/ Universidade de Hull, Inglaterra

Instituição: Universidade de Aveiro, Portugal (Professor Associado c/ Agregação)

Endereço: Campus Universitário de Santiago, 3810-193 Aveiro, Portugal

E-mail: anabelapereira@ua.pt

\section{Inês Magalhães}

Mestranda em Gerontologia/ Departamento de Psicologia e Educação/ Universidade de Aveiro Instituição: Universidade de Aveiro, Portugal

Endereço: Campus Universitário de Santiago, 3810-193 Aveiro, Portugal

E-mail: ines.amaral.osorio@ua.pt

\section{Diana Luzio}

Mestrado em Educação para a Saúde/ Faculdade de Medicina da Universidade do Porto Instituição: CINTESIS/Universidade de Aveiro

Endereço: Campus Universitário de Santiago, 3810-193 Aveiro, Portugal

E-mail: dianaluzio3@gmail.com 


\title{
Simone Lameiro
}

Mestrado em Gerontologia

Instituição: APACID - Associação de Apoio a Cuidadores de Pessoas Dependentes

Endereço: Junta de Freguesia de São Bernardo, R. Cónego Maio 133 1ºndar, 3810-089 Aveiro, Portugal

E-mail: simonelameiro@hotmail.com

\section{Mariana Van Zeller}

Mestrado em Psicologia Clínica e da Saúde

Instituição: APACID- Associação de Apoio a Cuidadores de Pessoas Dependentes

Endereço: Junta de Freguesia de São Bernardo, R. Cónego Maio $1331^{\circ}$ Andar, 3810-089

E-mail: marianavzbriosa@gmail.com

\section{RESUMO}

O cuidador informal, na sua prática de cuidados, experimenta de igual forma sentimentos positivos e negativos. No entanto, é a interpretação pessoal sobre a tarefa que executa que determina o seu grau de satisfação ou insatisfação em relação à mesma. OBJETIVO: Verificar os principais motivos de satisfação e/ou insatisfação dos cuidadores informais em relação à tarefa de cuidar. MÉTODO: Estudo de cariz qualitativo e paradigma interpretativo. Participaram 24 cuidadores familiares residentes no distrito de Aveiro, Portugal. A análise de conteúdo foi realizada com o apoio do software webQDA. RESULTADOS: Verificou-se que interpretação subjetiva que cada cuidador faz sobre a tarefa de cuidar determina a sua satisfação/insatisfação com a mesma. CONCLUSÃO: Mesmo que os cuidadores manifestem sentimentos de satisfação e insatisfação, prevalecerá o sentimento de solidariedade/generosidade do cuidador em relação ao familiar que se encontra incapacitado.

Palavras-chaves: cuidador familiar, relacionamento familiar, satisfação, insatisfação, gestão do cuidado

\begin{abstract}
The familiar caregiver experience both positive and negative feelings when taking care of his relative. However, is the subjective interpretation regarding the task he handles that will determine his satisfaction or dissatisfaction level. OBJECTIVE: To assess the main aspects of satisfaction / dissatisfaction of familiar caregivers towards the care task. METHOD: Qualitative study and interpretative paradigm. 24 caregivers living in the district of Aveiro, Portugal, participated in the study. The content analysis was performed with the support of the webQDA software. RESULTS: It was observed that the subjective interpretation made by each caregiver about the care task will determine his satisfaction/ dissatisfaction. CONCLUSION: Even when caregiver express satisfaction and dissatisfaction feelings, the caregiver's solidarity/ generosity feeling towards the disabled relative will prevail.
\end{abstract}

Key words: familiar caregiver, family relationship, satisfaction, dissatisfaction, handling the care 


\section{INTRODUÇÃO}

O avanço tecnológico na área da saúde, conjugado com as baixas taxas de natalidade e melhores condições de vida, têm contribuído para o aumento da longevidade da população do mundo contemporâneo. Este aumento da esperança média de vida impõe à sociedade atual desafios, que atingem vários domínios, entre os quais: aumento da capacidade de atendimento em saúde, aumento do número de reformados, além da necessidade de prestação de cuidados de longa duração que deverão ser efetuados no domicílio por algum membro familiar (Sequeira, 2010).

Contudo, viver mais tempo nem sempre poderá ser compreendido como um aspeto positivo. Quanto maior o avanço da idade, maiores são os riscos de o indivíduo padecer de uma doença incapacitante, que exigem cuidados especiais e contínuos. Será neste contexto que as famílias serão chamadas para assumir a responsabilidade pelos cuidados do familiar que se encontra incapacitado (Paúl, 1997 ; Gonçalves-Pereira \& Sampaio, 2011; Pereira, 2013)

É neste cenário que surge a figura do cuidador informal familiar que geralmente, sem uma formação específica para atuar neste contexto, ficará encarregue pela execução, supervisão, orientação e acompanhamento dos cuidados necessários ao familiar que se encontra dependente (Silva, 2009). Diversos autores como Brito, (2000); Figueiredo, (2007) ; Lage (2007) e Pereira, (2013) realçam o quão complexo e exigente é a tarefa de cuidador informal. É importante salientar que parte dos resultados dos estudos realizados por estes autores dão ênfase às questões relacionadas com a sobrecarga, seja ela objetiva ou subjetiva, manifestada pelos cuidadores quando estão no exercício da tarefa de cuidador informal.

É comum, durante o desenvolvimento da tarefa, o cuidador familiar manifestar um conjunto de impressões pessoais que podem estar diretamente relacionadas com as situações desagradáveis que envolvem esta atividade, sendo este o motivo pelo qual a forma de cuidar será fortemente influenciada pelo conjunto de crenças, experiências e vivências adquiridas ao longo da trajetória de vida do cuidador e familiar a ser cuidado (Campos, 2007).

É nesta linha de raciocínio, anterior à doença, que se situam os conflitos, mágoas e ressentimentos vivenciados entre o familiar incapacitado e o cuidador informal familiar. Ou seja, verifica-se que estes aspetos podem vir à tona durante o exercício da tarefa de cuidar, uma vez que esta tarefa é exigente, confrontando o cuidador com diversas situações que lhe podem causar desconforto e insatisfação (Neri \& Sommerhalder, 2006). Ao deixar que esses sentimentos venham à tona, o cuidador poderá comprometer a qualidade dos cuidados prestados ao seu familiar. 
Este estudo procurou revelar os sentimentos manifestados pelo cuidador na realização da tarefa de cuidados. Para tal foi realizada a seguinte questão: De que forma os cuidadores familiares geram sentimentos de satisfação e/ou insatisfação, durante o desempenho da tarefa de cuidados?

\section{ADOECIMENTO E FAMÍLIA}

O cuidar assume uma forma própria em todas as culturas. Regra geral, são as famílias que se responsabilizam e que assumem os cuidados, sendo o espaço familiar o local onde é tomado conhecimento da necessidade de início de cuidados ao familiar incapacitado ou doente. Contudo, a sua execução sofrerá influência da cultura na qual a família esta inserida (Santos, 2005).

Na perspetiva de Araújo, Paúl, \& Martins, (2011), a família é a base fundamental para o desenvolvimento e socialização dos indivíduos, é o local de chegada, permanência e partida, além de também ser um local de liberdade, afirmação, estabilidade e segurança para os seus membros. Para (Serra, 2002), o espaço familiar é visto como o local essencial para a troca mútua de sentimentos, para a resolução de conflitos e de problemas entre os seus elementos.

$\mathrm{Na}$ atualidade, devido ás constantes mudanças de padrões de relacionamento, é comum a família, durante sua trajetória de vida, vivenciar situações de perdas, divórcios e doenças, que poderão contribuir para a sua desordem e desestrutura (T. Martins, Ribeiro, \& Garrett, 2003). No entanto, segundo esses autores, após experienciar eventos dessa natureza, a família consegue superálos e segue em frente com o seu ciclo de vida.

Cardoso (2011), considera a família como um sistema complexo, constituído pelo comportamento e personalidade de cada membro familiar. Estes aspetos por sua vez repercutirão em toda a estrutura e funcionamento da dinâmica familiar. Desta forma, cada vez que um elemento tiver o seu bem-estar abalado, o impacto desse evento poderá acarretar alterações no bem-estar dos outros elementos familiares, como refere Ptacek et al. (1994, citado in Cardoso, 2011).

Quando um elemento familiar necessita de cuidados, toda a dinâmica familiar poderá ser afetada, e como consequência bons ou maus sentimentos, vivenciados anteriormente à doença entre os membros familiares, poderão vir á tona. Este tipo de situação despoleta, frequentemente, entre os membros familiares diferentes sentimentos, positivos ou negativos (Cardoso, 2011).

Apesar dos familiares terem vivenciado perturbações nos seus relacionamentos durante outras etapas do seu desenvolvimento, e pelo facto de o cuidar ser visto como um dever e uma obrigação familiar, a família em situação de doença tem tendência a organizar-se de forma a que um de seus membros assuma a responsabilidade pelos cuidados, tendo em vista as normas e padrões 
socioculturais exigidos pelo contexto social no qual está inserida (Baum \& Page, 1991; Neri \& Sommerhalder, 2006).

É de referir que o sentimento de dever e obrigação tem caráter ideológico, uma vez que se encontra relacionado com as tradições, padrões e normas de cada cultura, ou ainda pela conceção de vida e história de cada indivíduo (Figueiredo, 2007). Desta forma, fica evidente a existência de uma dívida, quer seja a nível de reconhecimento, quer seja a nível financeiro dos filhos para com seus pais, fazendo com que elementos afetivos e simbólicos se juntem num complicado jogo de reciprocidade (Portugal, 2011).

Assim sendo, constata-se que o indivíduo quando aceita cuidar de um familiar incapacitado, sendo muitas vezes a figura parental (pais), está preocupado em retribuir os sacrifícios realizados pelos filhos, e nos casos de cônjuges, fazer valer os compromissos assumidos no altar e válidos para toda vida. Caso contrário, poderão desenvolver sentimentos de culpa em relação a si próprios no contexto social no qual estão inseridos.

Portanto, quando um familiar aceita cuidar do seu familiar incapacitado, não significa que esqueceu os conflitos, mágoas e ressentimentos vivenciados por ambos em algum momento das suas vidas. Para Neri \& Sommerhalder (2006), a história pessoal, geracional e de parentesco entre cuidadores e pacientes, são aspetos de forte componente e estão interligados.

Segundo as autoras, bons e maus relacionamentos entre cônjuges, progenitores ou até mesmo progenitores dos cônjuges, envolvem um entrelaçamento complexo de pensamentos e sentimentos com várias nuances, que originam uma série de efeitos que determinarão a forma como cada cuidador irá cuidar de seu familiar. Na perspetiva das autoras, Neri e Sommerhalder (2006), "a dinâmica de cuidar e ser cuidado pode fazer aflorar sentimentos negativos antigos que estavam guardados e a situação pode ficar de difícil manejo" (p.29).

\subsection{SATISFAÇÃO E INSATISFAÇÃO ASSOCIADAS À PRESTAÇÃO DE CUIDADOS INFORMAIS}

Apesar da maioria dos trabalhos de investigação sobre este tema indicarem os efeitos negativos que a tarefa de cuidados têm sobre o cuidador informal, é possível identificar na literatura investigações que contrariam estes aspetos, como os estudos de Ashworth \& Baker, (2000), Martins (2007) e (Figueiredo (2007). Estes estudos revelam que a descoberta de novas habilidades, o sentimento de tornar-se útil, de obter reconhecimento social, constatar que a pessoa que cuida está bem tratada e feliz e, poder ficar mais próximo do seu familiar, são alguns dos elementos que na opinião dos cuidadores investigados fazem com que a tarefa de cuidador traga satisfação. 
No que diz respeito aos aspetos negativos, além de estarem relacionados com a sobrecarga, estão também estão associados às relações interpessoais, transgeracionais e de parentesco desenvolvidas ao longo da trajetória de vida de cada família (Falcão \& Bucher-Maluschke, 209).

Segundo a opinião de Falcão e Bucher-Maluschke (2009), os aspetos negativos da função de cuidador, também estão relacionados com a forma como os cuidadores avaliam a situação de cuidado que, por sua vez, estão relacionados com a disponibilidade de redes de apoio, estratégias de enfrentamento próprias de cada cuidador e de cada sistema familiar, com o significado que o cuidar tem para todos os envolvidos no processo, com a forma como cada membro familiar irá gerir o stress, e o que fará para encontrar conforto emocional, além dos aspetos relacionados com a personalidade e os relacionamentos anteriores à doença.

Assim, verifica-se que o cuidador informal, no desempenho de sua tarefa, pode experimentar de igual forma sentimentos positivos ou negativos (Kramer, 1997). No entanto, será a interpretação subjetiva que cada cuidador faz sobre a sua tarefa que determinará o grau de satisfação ou não em cuidar (Figueiredo, 2007).

Este artigo é uma fração do projeto de investigação denominado Autocuidado: Intervenção psicoeducativa para o desenvolvimento de competências pessoais/sociais do cuidador familiar.

O objetivo deste artigo foi verificar os principais aspetos de satisfação e/ou insatisfação de cuidadores informais em relação à tarefa de cuidar. Neste estudo, são apresentados os resultados de duas perguntas contempladas no guião de entrevista aos cuidadores informais, relativamente à satisfação e insatisfação no cuidar.

\section{METODOLOGIA}

A metodologia utilizada foi de natureza qualitativa e paradigma interpretativo. Neste estudo participaram 24 cuidadores informais. Os participantes, 14 sujeitos do sexo feminino e 2 sujeitos do sexo masculino, eram acompanhados pela Unidade de Saúde Familiar (USF) de Ovar e 5 sujeitos do sexo feminino e 3 do sexo masculino eram acompanhados pela Unidade de Cuidados na Comunidade (UCC), do Centro de Saúde de Aveiro (Portugal).

Todos os participantes foram selecionados por conveniência pela equipe de enfermagem das respetivas unidades de saúde. A primeira abordagem foi feita através de contato telefônico para verificar a aceitação dos utentes quanto à participação no estudo. As entrevistas tiveram a duração de aproximadamente uma hora e ocorreram nas instalações das unidades de saúde, no período de Março de 2015 a Janeiro de 2016. 
O instrumento de recolha foi entrevista por formulário. Os temas abordados no Formulário de Entrevista foram: sociodemográficos; relacionamento familiar; grau de satisfação ou não com a tarefa de cuidados; e as perspetivas de futuro. A análise de conteúdo foi realizada a partir da teoria de Bardin (2000), e suportada pelo software de apoio à análise qualitativa webQDA 2.0. .

\section{RESULTADOS}

São vários os estudos, entre os quais os de (Nolan, Grant, \& Keady, 1998), que indicam que as razões para a satisfação com a tarefa de cuidador informal podem ter várias proveniências, permanecendo relacionadas com as dificuldades. Apesar de toda a complexidade que envolve a tarefa de cuidados informais, a disponibilidade e vontade do cuidador em prestar cuidados estará sempre relacionada com a sua necessidade de sentir-se gratificado ou recompensado no seu papel de cuidador informal, é o que referem Mafullul e Morriss (2000, citado in Figueiredo, 2007).

De entre os itens analisados, provenientes dos resultados de duas questões da entrevista por formulário, serão descritas as 6 principais questões levantadas a partir da associação de elementos vinculados à questão de investigação com apoio do software de análise qualitativa (conforme figura abaixo).

Figura 1 - árvore de questionamentos, Fonte: webQDA

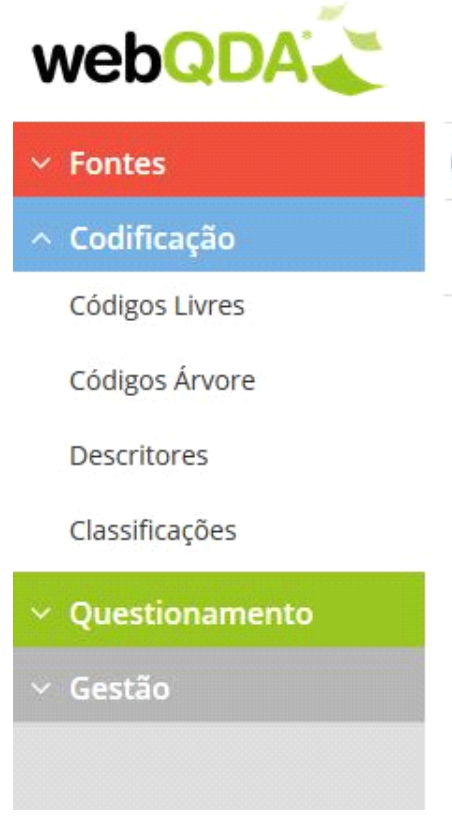

\section{CUIDADOR INFORMAL. FAMILIAR: RELAÇÃOO} Códigos Árvore
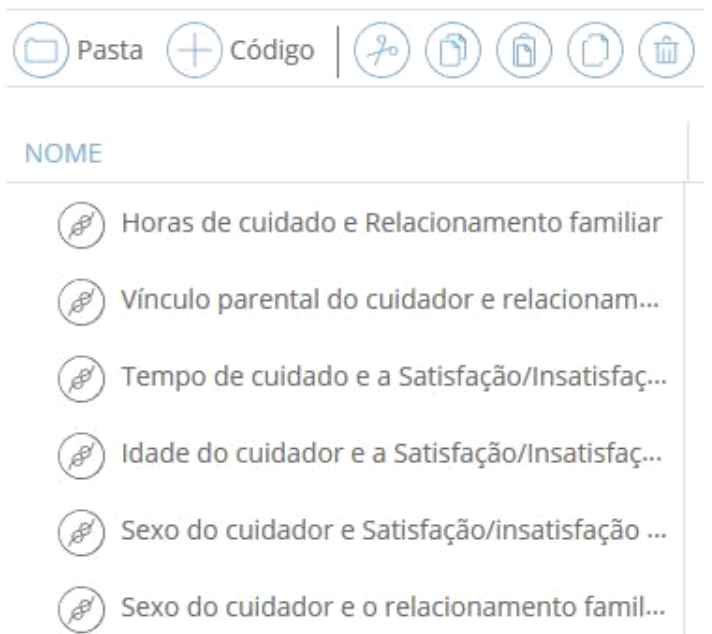

Os dados serão apresentados através do número de referências a cada um dos questionamentos descritos, na qual serão realçados os itens mais referenciados. Serão também apresentadas frases dos participantes, de forma a exemplificar a sua vivência. 


\subsection{HORAS DE CUIDADO E RELACIONAMENTO FAMILIAR}

A associação entre as horas diárias despendidas ao cuidado e o relacionamento familiar, revelou 36 referências dos participantes, sendo que a maioria está relacionada ao cuidado em tempo integral (26 referências). No que diz respeito ao Bom relacionamento - Satisfação (26 referências), a principal associação foi com a categoria Companheirismo/cumplicidade (11 referências).

No que toca o Relacionamento Conflituoso - Insatisfação (9 referências), são vistas associações com as categorias de Discórdias (3 referências) e Desrespeito (2 referências). Nesta associação, ficou evidente que tanto os aspetos positivos (afeto, companheirismo/cumplicidade e respeito), quanto os negativos (desconfiança, desrespeito e discórdia) de Bom relacionamento -

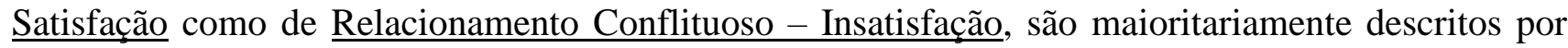
aqueles que despendem maior tempo a cuidar (tempo integral), quer seja pela maior evidência dessas ações pelo tempo que passam juntos ou pelo maior número de unidades de texto compreendidos nesta categoria.

Assumir a responsabilidade de cuidar de um familiar incapacitado, trás repercussões em vários níveis da vida do cuidador familiar. As exigências oriundas dessa tarefa impõe ao cuidador alguns ajustes à sua antiga rotina, além de exigirem alterações na sua própria dinâmica familiar, o que pode fazer com que este manifeste algum sentimento de descontentamento em relação à sua vida pessoal atual (Figueiredo \& Sousa, 2008; Pereira, 2013). Conforme revelou o cuidador 5:

"eu preferia que tudo estivesse correndo na normalidade nas nossas vidas, eu ir trabalhar, fazer as coisas, era simples. Como a vida deu essa volta?!” (CF-5).

Desempenhar essa tarefa em tempo integral pode originar no cuidador desgaste físico e mental, além de estados emocionais negativos, que por sua vez vão interagir com formas inadequadas de gestão do cuidado (Brito, 2000; Neri \& Sommerhalder, 2006; \& Sequeira, 2010).

Todavia, será a perceção subjetiva que cada cuidador tem sobre o quanto esta atividade afeta a sua vida, diminuindo o tempo despendido em atividades que levam em conta as suas necessidades pessoais, que podem fazer despoletar no cuidador sentimentos que irão determinar a qualidade da prestação de cuidados, como referiu a cuidadora 2 :

"eu não tenho gosto nenhum em cuidar dela, não é o que eu gosto, eu me sinto tranquila em ser eu a cuidar dela, mas eu não me sinto satisfeita em cuidar dela" (CF-2). 
Na perspetiva de Neri e Sommerhalder (2006), cuidadores que se sentem sobrecarregados, injustiçados e que acumulam tarefas familiares e profissionais, tendem a sentir-se fragilizados e o desempenho de suas tarefas pode ficar aquém de suas capacidades.

\subsection{VÍNCULO PARENTAL DO CUIDADOR E RELACIONAMENTO FAMILIAR}

$\mathrm{O}$ resultado da associação entre o vínculo parental do cuidador e o relacionamento familiar apontou 36 referências dos participantes. No que respeita o Bom relacionamento - Satisfação foram verificadas 27 referências e entre Relacionamento Conflituoso - Insatisfação, 9 referências. Nos dois casos são verificadas maiores associações com as perceções do(a)s filho(a)s (18 referências) e dos cônjuges (14 referências).

Verifica-se ainda que o (a)s filho(a)s descrevem em maior quantidade (16 unidades de texto) os aspetos do relacionamento familiar satisfatório, na qual, referem características de companheirismo e cumplicidade (08 unidades de texto) no cuidar, afeto (04 unidades de texto) e 04 unidades de texto de respeito.

Os cônjuges também descrevem situações evidenciadas do companheirismo (05 unidades de texto). Contudo, são os que mais referem as situações do relacionamento familiar insatisfatório com exemplos de desconfiança (02 unidades de texto), desrespeito (03 unidades de texto) e discórdias (02 unidades de texto).

Este resultado perspetiva que os cuidadores informais familiares vivenciam na prática diária de cuidados, uma dualidade de sentimentos e emoções. Constata-se que ao mesmo tempo que os cuidadores manifestam sentimentos de companheirismo/cumplicidade, afeto e reciprocidade, podem também percecionar situações de desrespeito, desconfiança e discórdias para com o familiar incapacitado. Esta complexa rede de sentimentos, pode estar associada aos conflitos, ás mágoas e aos ressentimentos vividos por ambos os intervenientes no decorrer de seus ciclos de vida (Kramer, 1997 ;Falcão \& Bucher-Maluschke, 2009).

No que respeita o (a)s filho(a)s, observa-se, através deste estudo, que são eles que mais mantêm contato com o familiar cuidado, numa situação de companheirismo, cumplicidade e afeto. Uma das justificativas para este fato consiste em que o(a)s filho(a)s geralmente estabelecem com suas mães histórias de relações mais intensas e íntimas (Andrade, 2009) como revela a cuidadora 11,

"sempre fomos muito unidas, muito intimas, muito ligadas, era uma relação muito próxima de cumplicidade” (CF-11). 
Quando mãe e filha no decorrer de seus ciclos de vidas, conseguem manter um padrão de relacionamento baseado nestes princípios, provavelmente, quando a filha se tornar cuidadora de sua mãe, por mais exigente que seja a tarefa, a filha cuidadora poderá estar mais disponível para atender às necessidades de sua mãe (Andrade, 2009).

No que toca aos cônjuges, é possível verificar que estes sinalizam sentimento negativos e algumas insatisfações, porém estas não estão desvinculadas de conflitos vivenciados anteriormente à doença, ao contrário, tais conflitos estão subjacentes na relação entre cuidador e paciente. Portanto o compromisso pessoal assumido perante o altar, faz com que ambos assumam a responsabilidade pelos cuidados de forma compartilhada (Neri e Sommerhalder, 2006), como revela a cuidadora 14 sobre o relacionamento com o seu cônjuge,

"é um dever que tenho, eu assumi as palavras que eu disse no dia 8 de dezembro no meu casamento. Eu assumi as palavras do altar, olhar por ele mesmo doente e ele também disse para mim” (CF-14).

\subsection{TEMPO DE CUIDADO E A SATISFAÇÃO/INSATISFAÇÃO NO CUIDAR}

Relativamente à associação entre o tempo que desempenha a tarefa de cuidador e a satisfação/insatisfação em cuidar, o resultado deste estudo denotou 25 referências. Verificou-se neste estudo, que os cuidadores que cuidam entre 6 e 10 anos (8 referências), demonstram maior satisfação em cuidar e que esta satisfação está associada com a subcategoria sentimento de reciprocidade (4 unidades de texto) e dever familiar (2 unidades de texto).

Quando um membro familiar aceita cuidar de um ente querido, fá-lo por acreditar que cuidar nessas circunstâncias é sua responsabilidade moral associado à necessidade de dever cumprido perante o familiar e o contexto no qual está inserido, o que ocasionará um ato de reciprocidade (Paquet, 1995). Nesta perspetiva a cuidadora 12 descreve:

"olha, porque tenho a minha mãe e valha-me Deus, presto os cuidados que ela precisa. Às vezes às pessoas perguntam dela, olha que coisa boa, já com 100 anos" (CF-12).

Sobre o sentimento de reciprocidade, (Nolan, Grant, \& Keady, 1996), sublinham que este aspeto é o que mais se enquadra para a compreensão da dádiva e aceitação de ajuda, como relata a cuidadora 3 , 
"porque a minha mãe merece. Eu gosto muito dela, minha mãe deu-me muito carinho e muito amor" (CF-3).

Segundo os mesmos autores, no âmbito dos cuidados informais, a reciprocidade não está diretamente relacionada com uma troca equitativa de ajuda ou suporte, ao contrário, ela é o resultado de várias negociações, justificadas pela história e biografia das relações. Além disso a reciprocidade permite analisar as satisfações associadas à prestação de cuidados informais.

\subsection{IDADE DO CUIDADOR E A SATISFAÇÃO/INSATISFAÇÃO NO CUIDAR}

Referente à associação da idade do cuidador e a satisfação/insatisfação no cuidar foram verificadas 25 referências, sendo 20 para a satisfação no cuidar e 9 relacionadas a insatisfação no cuidar. Na faixa etária entre 40-50 anos e 50-60 anos, verifica-se um maior número de unidades de texto (15 referências) e nesta faixa etária, também são verificados um maior número de cuidadores que, em sua maioria, estão satisfeitos em cuidar de seu familiar (11 unidades de texto).

De acordo com os estudos de (Jani-Le Bris, 1994), o perfil dos cuidadores informais atualmente são: mulheres de meia-idade, que cuidam de mais de uma pessoa e não recebem qualquer ajuda, seja para as tarefas domésticas, seja para o cuidado.

Embora nessa faixa etária seja comum o indivíduo adulto ser produtivo e estar no mercado de trabalho, este estudo revelou que os cuidadores mesmo estando sem atividade laboral remunerada e desempenhando uma tarefa com pouco realce, como é a de cuidador informal familiar, podem demonstrar satisfação. Esta satisfação, por sua vez, pode estar relacionada com o facto de o cuidador se sentir gratificado por, nessa fase de sua vida, ter a oportunidade de estar a cuidar do seu familiar. Neste âmbito, a cuidadora 6 afirma,

"Estou satisfeita porque sei que ele é bem cuidado, porque não é mal nenhum ele estar lá, é um ser que merece respeito e amor de mim” (CF-6).

\subsection{SEXO DO CUIDADOR E SATISFAÇÃO/INSATISFAÇÃO NO CUIDAR}

Com relação a esta associação, verificou-se que as mulheres que participaram deste estudo (20 referências) descrevem mais sobre as suas perceções relacionadas à tarefa de cuidar do que os homens (5 referências). Contudo, é importante salientar que o maior número de participantes do estudo era do sexo feminino (19 cuidadoras) e apenas 5 cuidadores eram do sexo masculino. 
É notório que, quando são chamadas para o desempenho da tarefa de cuidados, as mulheres são as que mais expressam o sentimento de dever para cuidar do familiar (6 unidades de texto), além disso, referem maior confiança no seu próprio cuidado (4 unidades de texto) e também realçam situações de satisfação pela reciprocidade da relação com o familiar (4 unidades de texto).

A partir do momento que surge a necessidades de cuidar de um familiar, regra geral, será a mulher a principal responsável pelos cuidados familiares (Neri \& Sommerhalder, 2006). No que respeita ao sexo masculino, no âmbito desta investigação, ainda são em minoria, sendo que na maioria das vezes essa situação ocorre nas situações conjugais, o que faz com que assumam este papel mobilizados pelo compromisso marital (Ribeiro, 2005).

Os estudos de García (2010) identificam certas perceções e valorizações inerentes à tarefa de cuidador, ao mesmo tempo que a interpretam como um padrão de comportamento considerado normal. Os resultados dessa pesquisa sublinham que na perceção do cuidador, cuidar de um familiar é visto como um dever pessoal ou moral, mesmo que seja uma atividade de extrema exigência ou sacrifício, como pode ser notado a partir da fala da cuidadora 3:

"Eu fico satisfeita ao cuidar da minha mãe, porque graças a Deus eu tenho saúde e disponibilizei saúde e meu tempo e acho que é nosso dever cuidar dos nossos" (CF$3)$.

García, (2010) analisa ainda a perceção do dever ou obrigação a partir dos diversos tipos de vínculos parentais, constatando que quando os cônjuges e filhos invocam questões relacionadas com dever ou obrigação moral, estas estão interligadas com questões de natureza amorosa e/ou sentimental. Desta forma, fica evidente que para os cuidadores o sentido de dever está relacionado com o sentimento de solidariedade familiar, como é descrito pelo cuidador 2:

"Estou fazendo um bem a alguém, principalmente sendo da família e lá está, não sabemos o dia de amanhã (...)" (CF-2).

\subsection{SEXO DO CUIDADOR E O RELACIONAMENTO FAMILIAR}

Sobre este aspeto, o presente estudo revelou que as mulheres cuidadoras referem em maior número de referências possuir um bom relacionamento com o familiar cuidado. Contudo, a partir do cruzamento entre sexo e relacionamento familiar, são visualizados os sentimentos de relacionamentos conflituosos ( 9 referências) existentes com o familiar que cuidam, sendo a 
desconfiança (02 unidades de texto), desrespeito (03 unidades de texto) e situações de discórdia (03 unidades de texto). Fica evidente que as referências do bom relacionamento com o cuidador, prevalecem com o total de 27 referências, independentemente do sexo. As mulheres descrevem 23 referências no âmbito do afeto, companheirismo/cumplicidade e respeito e os homens 4 referências.

A história familiar é construída a partir de relacionamentos interpessoais que estabelecem a identidade de cada um dentro do sistema (Wanderbroocke, 2005). Segundo Neri \& Sommerhalder (2006), as avaliações subjetivas que cada cuidador faz sobre o seu relacionamento com o familiar cuidado, recebem influência do contexto social no qual estão inseridos, das crenças, das prioridades e valores do cuidador, que serão regidas pela sua relação atual e passada com o ente querido recetor de cuidados.

$\mathrm{Na}$ opinião destas autoras, a história pessoal, geracional e de parentesco desenvolvidas entre cuidador e familiar serão determinantes para a qualidade dos serviços prestados. Nesse âmbito, a cuidadora 9, a partir das experiências das relações conflituosas no passado com o seu cônjuge, refere que:

“(...) ele começou a andar com outras mulheres que eram minhas amigas e aí eu piorei. E foi assim a minha vida, deixei andar, deixei andar... e hoje eu digo meu Deus, se fosse hoje há uns anos atrás eu não fazia o que fiz, naquela altura a pessoa não pensa e podia ter dado uma volta na minha vida que não dei. Foi o único homem que conheci e às vezes ainda penso, então meu Deus, eu tenho a necessidade de aturar isso? Ele não é meu marido, ele é meu companheiro (...) mas é a vida” (CF-9).

A cuidadora 5 revela com carinho as lembranças do bom relacionamento ao descrever:

"Era muito bom, ele era muito carinhoso, entendíamo-nos muito bem, não dávamos um passo sem o outro, éramos muito companheiros, nunca nos faltamos ao respeito um ao outro. Foi muito difícil ver ele adoecer, pois ele começou a ficar debilitado também da cabeça e agora não é o que já foi” (CF-5).

Vê-se, portanto, que os bons e maus relacionamentos anteriores à doença, vivenciados entre cuidadores e cônjuges, progenitores ou até mesmo com progenitores dos cônjuges, produzem um entrelaçamento de sentimentos que poderão assumir várias formas, podendo influenciar a qualidade das tarefas prestadas ao familiar incapacitado (Neri \& Sommerhalder, 2006). 


\section{CONCLUSÃO}

A situação de adoecimento prolongado no seio familiar será um acontecimento marcante e que terá implicações em todos os níveis da dinâmica familiar. Lidar diariamente com tarefas desgastantes, conviver com o sofrimento do doente e ainda ter que suportar mágoas, conflitos e ressentimentos, que muitas das vezes foram vivenciados pelos cuidadores e o recetor de cuidados anteriormente à doença, tornam o cuidador informal familiar vulnerável e fragilizado diante das exigências impostas pela tarefa de cuidados.

Especificamente no que respeita aos conflitos vivenciados anteriormente à doença, de acordo com os resultados deste estudo, ficou evidente que será a avaliação subjetiva que cada cuidador tem sobre a tarefa que determinará o seu grau de satisfação ou insatisfação em relação à tarefa que executa.

Constatou-se também neste estudo, que mesmo sendo o cuidador confrontado com situações de mágoas e ressentimentos e, por mais que estas questões ainda não tenham sido resolvidas com o seu familiar que necessita de cuidados, no momento em que a família é confrontada com situações de doença, prevalecerá entre os familiares o sentimento de solidariedade e reciprocidade, e alguém do seio familiar se responsabilizará pelos cuidados do familiar.

Desta forma, o objetivo deste estudo foi atingindo na medida em que foi possível identificar que os cuidadores familiares tanto podem manifestar sentimentos de satisfação e/ou insatisfação, no processo de cuidar. Verificou-se que os relacionamentos interpessoais em contexto familiar são elementos essenciais para a compreensão das relações estabelecidas entre cuidador e familiar incapacitado.

Portanto, conclui-se que mesmo que existam conflitos anterior à doença, e mediante os desafios associados à tarefa de cuidar, o cuidador informal familiar estará disposto a dar o seu melhor para oferecer conforto e bem-estar ao seu familiar incapacitado, bem como vivenciar aspetos de satisfação na tarefa de cuidar. 


\section{REFERENCIAS}

Andrade, F. M. M. (2009). O cuidado informal á pessoa dependente em contexto domiciliário: necessidades educativas do cuidador principal (Master's thesis, Instituto de Educação e Psicologia, Universidade do Minho). Retrieved from http://hdl.handle.net/1822/10460

Araújo, I., Paúl, C., \& Martins, M. (2011). Famílias cuidadoras de idosos: Estrutura e desenvolvimento. Ciência, Cuidado e Saúde, 10(3), 452-458. Retrieved from https://scholar.google.pt

Ashworth, M., \& Baker, A. (2000). Time and space: Carers' views about respite care. Health \& Social Care in the Community, 8(1), 50-56. Retrieved from http://onlinelibrary.wiley.com/doi/10.1046/j.1365-2524.2000.00221.x/full

Baum, M., \& Page, M. (1991). Caregiving and multigenerational families. The Gerontologist, 31(6), 762-769. Retrieved from http://gerontologist.oxfordjournals.org/content/31/6/762.short

Brito, M. L. S. (2000). A saúde mental dos prestadores de cuidados a familiares idosos (Master's thesis, Faculdade de Medicina, Universidade do Porto).

Campos, E. P. (2007). Quem cuida do cuidador (3rd ed.). Petrópolis-RJ: Vozes.

Cardoso, M. J. S. P. (2011). Promover o bem-estar do familiar cuidador: Programa de intervenção estruturado (Doctoral dissertation, Instituto de Ciências da Saúde, Universidade Católica Portugesa).

Falcão, D. da S., \& Bucher-Maluschke, J. (2009). Cuidar de familiares idosos com a doença de alzheimer: Uma reflexão sobre aspetos psicossociais. Psicologia Em Estudo, 14(4), 777-786. Retrieved from http://www.scielo.br/pdf/pe/v14n4/v14n4a18

Figueiredo, D. (2007). Cuidados familiares ao idoso dependente. Lisboa: Climepsi Editores.

Figueiredo, D., \& Sousa, L. (2008). Percepção do estado de saúde e sobrecarga em cuidadores familiares de idosos dependentes com e sem demência. Revista Portuguesa de Saúde Pública, 26(1), $15-24$.

García, J. (2010). Los tiempos del cuidado: El impacto de la dependence de los mayores en la vida cotidiana de sus cuidadores. Madrid: Ministério de Sanidad y Política Social/ Instituto de Mayores y Servicios Sociales (IMERSO.

Gonçalves-Pereira, M., \& Sampaio, D. (2011). Psicoeducação familiar na demência: Da clínica à saúde pública. Revista Portuguesa de Saúde Pública, 29(1), 3-10.

Jani-Le Bris, H. (1994). Responsabilidade familiar pelos dependentes idosos nos países das comunidades europeias. Lisboa: Fundação Europeia para a Melhoria das Condições de Vida e do Trabalho.

Kramer, B. (1997). Gain in the caregiving experience: where are we? What next? The Gerontologist, 37(2), 218-232. Retrieved from http://gerontologist.oxfordjournals.org/content/37/2/218.short

Lage, M. I. G. de S. (2007). Avaliação dos cuidados informais aos idosos: Estudo do impacte do cuidado no cuidador informal (Doctoral dissertation, Instituto de Ciências Biomédicas Abel Salazar, Universidade do Porto). 
Martins, R. (2007). Envelhecimento e saúde: um problema social emergente. Lisboa. Retrieved from https://repositorio.ipv.pt/handle/10400.19/614

Martins, T., Ribeiro, J., \& Garrett, C. (2003). Estudo de validação do questionário de avaliação da sobrecarga para cuidadores informais. Psicologia, Saúde \& Doenças. Retrieved from https://repositorio.ispa.pt/handle/10400.12/1050

Neri, A. L., \& Sommerhalder, C. (2006). As várias faces do cuidado e do bem-estar do cuidador. In Cuidar de idosos no contexto da família (2nd ed., pp. 9-58). Campinas-SP: Alínea Editora.

Nolan, M., Grant, G., \& Keady, J. (1996). Understanding family care. Buckingham: Open University Press.

Nolan, M., Grant, G., \& Keady, J. (1998). Assessing needs of family carers. A guide for practitioners. Brighton: Pavilion Publishing.

Paquet, M. (1995). La prévention auprés des personnes-soutien de personnes ãgées dépendantes. Quelle prévention? Canadian Social Work Review, 12, 45-71.

Paúl, C. (1997). Lá para o fim da vida. Idosos, famílias e meio ambiente. Coimbra: Almedina.

Pereira, H. R. (2013). Subitamente cuidadores informais - dando voz(es) às experiências vividas. Loures: Lusociência.

Portugal, S. (2011). Dádiva, família e redes sociais. In Cidadania políticas públicas e redes sociais (pp. 42-59). Coimbra: Imprensa da Universidade de Coimbra.

Ribeiro, O. (2005). Quando o cuidador é um homem: Envelhecimento e orientação para o cuidado. In Constança Paúl \& A. M. Fonseca (Eds.), Envelhecer em Portugal (pp. 231-254). Lisboa: Climepsi Editores.

Santos, P. A. L. (2005). O familiar cuidador em ambiente domiciliário (Master's thesis, Escola Nacional de Saúde, Universidade Nova de Lisboa).

Sequeira, C. (2010). Cuidar de idosos com dependência física e mental. Lisboa: Lidel.

Sequeira, J. M. P. S. R. (2005). Competências Psicológicas e treino mental (Tese de doutoramento, Universidade do Minho).

Serra, A. V. (2002). O stress na vida de todos os dias. Coimbra: Gráfica de Coimbra, Lda.

Silva, A. M. A. (2009). Efetividade de um programa de intervenção na perceção de sobrecarga dos familiares de pessoas idosas com demência (Master's thesis, Faculdade de Medicina, Universidade de Lisboa).

Wanderbroocke, A. (2005). Cuidando de um familiar com câncer. Psicologia Argumento, 23, 17-23. Retrieved from http://www2.pucpr.br/reol/index.php/PA?dd1=183\&dd99=pdf 